\title{
DESIGN, FABRICATION, AND CHARACTERIZATION OF A MICROTURBOPUMP FOR A RANKINE CYCLE MICRO POWER GENERATOR
}

\author{
Changgu Lee ${ }^{1}$, Mokhtar Liamini ${ }^{2}$, Luc G. Fréchette ${ }^{1,2}$ \\ ${ }^{1}$ Columbia University, Department of Mechanical Engineering \\ 220 Mudd bldg, MC 4703, New York, NY 10027, USA \\ ${ }^{2}$ Université de Sherbrooke, Department of Mechanical Engineering \\ 2500 boul. Universite, Sherbrooke, QC, J1K 2R1, Canada
}

\begin{abstract}
A microfabricated turbopump has been designed, fabricated and experimentally characterized as the core component of a micro steam turbine power-plant-on-a-chip, which aims to implement the Rankine thermal cycle for micro power generation. The device consists of a four-stage radial planar type turbine and a spiral groove viscous pump supported on gas-lubricated bearings. The device is composed of five wafers: one glass wafer, one SOI wafer, and three silicon wafers. The silicon and SOI wafers are patterned using shallow and deep reactive ion etching (total of 14 masks), while the Pyrex glass wafer are ultrasonically drilled. Anodic bonding, fusion bonding and manual assembly with alignment structures were then used to complete the device and enclose the $4 \mathrm{~mm}$ diameter rotor. In a test using compressed air to drive the turbine, the rotor was spun up to $116,000 \mathrm{rpm}$, which corresponds to $25 \mathrm{~m} / \mathrm{s}$ in tip speed producing $0.073 \mathrm{~W}$ of mechanical power, and the pump pressurized water by $88 \mathrm{kPa}$ with a flow rate of $4 \mathrm{mg} / \mathrm{s}$. The pump performance chart was also completely characterized for speeds up to $120,000 \mathrm{rpm}$. A 1-D pump model based on lubrication theory has shown close agreement with the data and predicted $7.2 \%$ of maximum pump efficiency over the range of operating speeds.
\end{abstract}

\section{INTRODUCTION}

As high-tech products such as portable electronics, distributed sensors, small scale actuators, and micro vehicles are being developed and improve in functionality, the demand is increasing for compact power sources with high energy and power per unit volume that could replace batteries with relatively low power density. MEMS heat engines have the potential for these applications, providing the benefits of high power production per unit volume from the small size, and low production cost from batch fabrication technology.

Among the heat engines, a micro Rankine cycle steam turbine is a good candidate for micro power generations, leveraging the technology developed for micro gas turbines [1]. The Rankine vapor cycle is similar to the Brayton gas cycle implemented in gas turbine engines in that they use turbines to convert fluid energy to mechanical energy. But, the critical difference is in the pressurization process, for which the gas cycle uses the air compressor, while the vapor cycle uses a liquid pump. Even though the gas cycle is typically able to achieve high efficiency by increasing the turbine inlet temperature, the viscous effect which dominates the efficiency of the compressor at small scales reduces the efficiency of the system as a whole. In contrast, the pump work in the vapor cycle is significantly small compared to the energy produced by the turbine such that it does not affect the overall efficiency of the system substantially, even at small scales. Therefore, the micro Rankine cycle steam turbine has the characteristics necessary to become an alternative to batteries in high power density applications due to its acceptable efficiency and low cost when incorporated with MEMS technology [2].

In order to demonstrate the concept of the micro Rankine power generation system, a microturbopump has been developed using silicon microfabrication techniques, such as deep etching and multiple wafer bonding. This device consists of a steam turbine and a viscous pump supported on a gas-lubricated bearing system, forming the core energy conversion component of the Rankine system. This paper presents our recent accomplishments in the development of this rotating subsystem for a Rankine power MEMS, complementing the turbine characterization previously reported [3].

\section{DEVICE LAYOUT AND DESIGN APPROACH}

The turbopump converts thermal-fluidic energy of flow through the turbine into mechanical energy to drive a pump and other loads acting on the rotor. The components of the device include a turbine, pump, main thrust bearing, auxiliary thrust bearing, journal bearing, and seals as illustrated in Figure 1. Pressurized gas comes into the inner radial position from the top side and flows radially outward through the blade rows of the turbine, spinning the rotor. Simultaneously, water is drawn from the bottom side by the pump with spiral groove patterns and is discharged to the center of the bottom side of the device. In order to prevent flooding in undesired areas, a seal with partial grooves is installed on the bottom side of the rotor surrounding the pump. A hydrostatic thrust bearing with small circular nozzles keeps the rotor axially balanced by supplying force from the bottom side against the pressure force acting on the turbine side. A hydrostatic journal bearing, which surrounds the rotor as a circular gap, helps keep lateral balance by providing a restoring force as described in previous work [4].

Among the components, the turbine and thrust bearing (TB) have novel configurations, different from the previous MEMS gas turbomachinery [1],[4]. The turbine has a multi-stage configuration to potentially achieve high pressure ratio for reasonable efficiency of the whole Rankine thermal system, and the thrust bearing system is designed to exert the thrust force only from one-side with the goal of developing a self-supporting bearing system. The pump and seal have spiral groove patterns on the surface to draw and pressurize the fluids using viscous drag. Especially, the dynamic pressurization of the seal due to the spiral patterns was necessary in order to ensure the successful performance of the pump by confining the liquid flow in the center area. The journal bearing (JB) was directly inspired from previous work at MIT [4].

Low order models have been developed and used for component and system-level design [5], including: 1) a turbine 
model based on mean line analysis with loss correlations extracted from CFD ; 2) a flow resistance model for the thrust bearing; 3) models based on lubrication theory for the pump and seal. They were combined to design a micro turbopump system with desired performance levels while satisfying power balance (production versus consumption), as well as rotor axial position balance. The device was designed to produce $4.7 \mathrm{~W}$ of mechanical power from steam with $200^{\circ} \mathrm{C}$ and $3 \mathrm{~atm}$ of turbine inlet conditions and to pump water pressurizing $4.5 \mathrm{~atm}$ at rotor tip speed of $260 \mathrm{~m} / \mathrm{s}$. The turbine, whose diameter is $4 \mathrm{~mm}$, has approximately 1200 blades with 100 um of chord length and 50 um of height, and the viscous pump has 16 grooves with 6 um of depth (Figure 2). The journal bearing is $380 \mathrm{um}$ deep and $10 \mathrm{um}$ wide when the rotor is centered. The thrust bearing consists of 34 nozzles with $10 \mathrm{um}$ of width and 85 um of depth [5].

\section{FABRICATION}

The complete device is made of five wafers as shown in Figure 1: one Pyrex glass wafer (wafer A), one silicon-oninsulator (SOI) wafer (wafer B), and three silicon wafers (wafers $\mathrm{C}, \mathrm{D}$, and $\mathrm{E}$ ). The glass wafer is mechanically machined using ultrasonic drilling, and the others are fabricated using photolithography, reactive ion etching (RIE), and deep reactive ion etching (DRIE). The processing of each wafer is illustrated in Figure 3 and goes as follows:

Wafer A: The holes are formed by ultrasonic drilling.

Wafer B: Using nested masks, the top side is deep etched twice to reach the oxide layer, and the other side is patterned and also etched to the oxide layer. Then, the oxide layer is removed by buffered oxide etchant (BOE) to complete through-wafer holes.
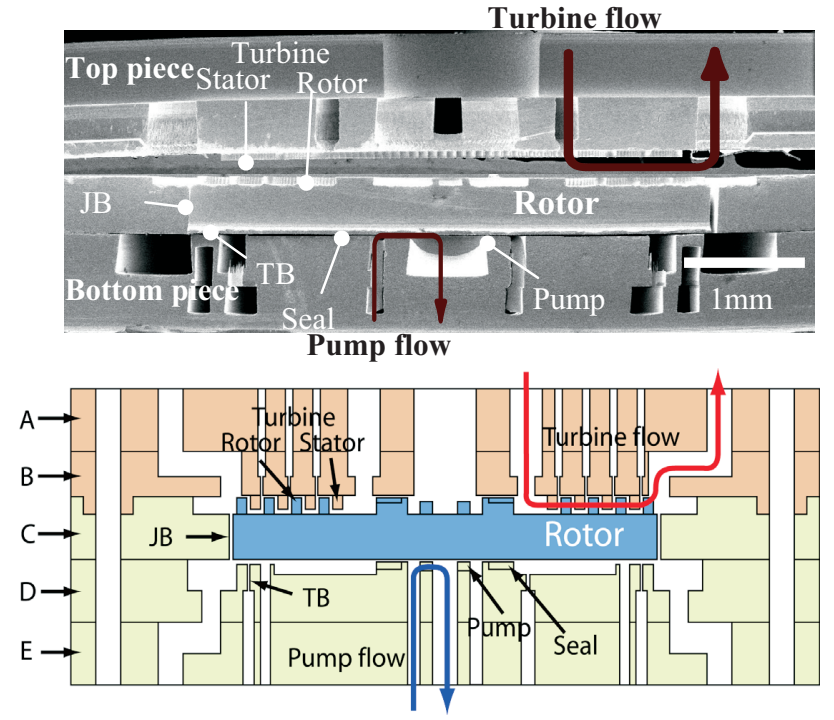

Figure 1. SEM image (top) and schematic (bottom) of the crosssection of a device. The letters (A to E) identify the 5 wafers.
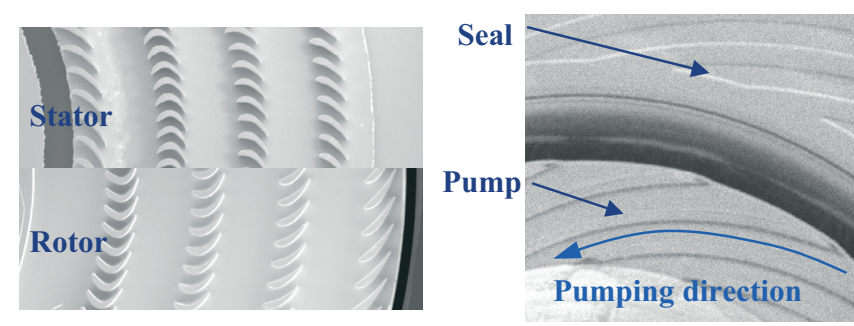

Figure 2. SEM images of turbine (left) and pump (right). The length of turbine blades is about 100um. The outer radius of the pump is 550 um. 


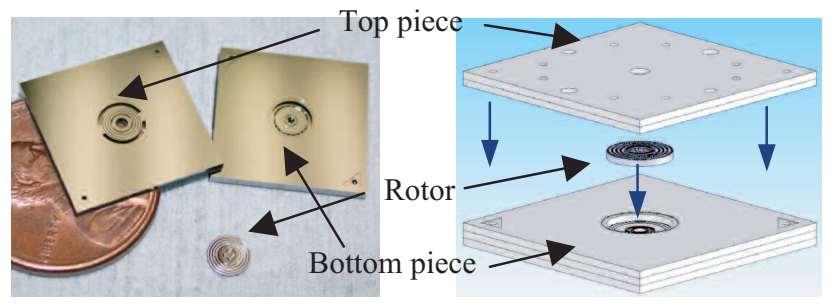

Figure 4. Micro turbopump device (left) and assembly process (right). The dimension of the assembled device is $15 \times 15 \times 2.3 \mathrm{~mm}^{3}$.

Wafer C: The top side receives a shallow etch at first, and a deep etch to form the rotor blades. Then, the oxide is deposited by plasma-enhanced chemical vapor deposition (PECVD) to protect the surface during the through etch from the other side. The journal bearing is created by a deep etch from the bottom side, defining the rotor. A glass handle wafer was attached to prevent the rotor from falling in the chamber when it is cut out. It is removed and kept separately from the wafer after clearing the oxide layer.

Wafer D: At first, the top side receives four shallow etches. Subsequently, the bottom side is etched half way through with the top side covered by an oxide layer for surface protection. Finally, the top side is patterned and etched until through holes are formed. Wafer E: The wafer is etched half way through from both sides to create channels and holes.

Overall 14 photomasks were used, and 4 shallow silicon etching, 10 deep silicon etching, and 3 PECVD oxide deposition steps were performed. After the wafers are completed, they go through the cleaning processes such as oxide removal using buffered oxide etchant (BOE) and MOS (or RCA) clean. Then, the wafers are aligned and contacted. The glass wafer and SOI wafer are pressed with a slight force of $25 \mathrm{~N}$ and remain in contact for 10 minutes in vacuum at $350{ }^{\circ} \mathrm{C}$, with 1000 Volts applied for anodic bonding. The other wafers are pressed with a force of $1700 \mathrm{~N}$ for 30 seconds in vacuum. They are then annealed at $1000{ }^{\circ} \mathrm{C}$ for 1 hour in the nitrogen environment for strong fusion bonding.

After completing the fabrication process, the device has three pieces as shown in Figure 4. The top piece is the stack of wafers $\mathrm{A}$ and $\mathrm{B}$, and the bottom piece the stack of wafers $\mathrm{C}, \mathrm{D}$, and $\mathrm{E}$. The device is assembled by inserting the rotor into the center hole of the bottom piece and aligning the top piece to the bottom piece using alignment features in the corners of the mating surfaces, which consist of triangular holes and circular pins.

\section{DEVICE CHARACTERIZATION}

The assembled device is placed in a test package, which is made of flexiglass. The channels in the device are connected to the package through rubber o-rings to allow supply and discharge of the working fluids (gas and liquid). Compressed air was supplied to operate the bearing system and drive the turbine. The gap between the rotor and the surface of the pump grooves was kept almost constant during the tests by regulating the thrust bearing flow rate, and was assumed to be $1 \mu \mathrm{m}$ in the modeling. Turbine and bearing operation have previously been characterized up to $300,000 \mathrm{rpm}[3]$.

To characterize the pump, water is introduced at its inlet with the flow controlled by a downstream valve and its flow rate is measured using a digital mass flow meter. Using this approach, the pump performance chart was completely characterized for speeds up to $120,000 \mathrm{rpm}$ (Figure 5). The pump valve was regulated to vary the flow rate from zero to maximum for a fixed rotor speed. A maximum pressure rise of $240 \mathrm{kPa}$ (valve closed) and maximum flow rate of $9 \mathrm{mg} / \mathrm{s}$ (valve fully open) were achieved at a speed of $120,000 \mathrm{rpm}$. The pump model has shown close agreement with the data and predicted $7.2 \%$ of maximum pump efficiency over the range of operating speeds, which is at least one order of magnitude superior to other MEMS pumps, with efficiencies typically less than $0.1 \%$.

The overall turbopump performance was characterized by keeping the valve opening fixed and measuring inlet and outlet conditions of the turbine and pump (Figure 6). In this test, the rotor was spun up to $116,000 \mathrm{rpm}$, which corresponds to $25 \mathrm{~m} / \mathrm{s}$ in tip speed, with $41 \mathrm{kPa}$ of turbine differential pressure and $24 \mathrm{mg} / \mathrm{s}$ of turbine flow rate, while the pump pressurized water by $88 \mathrm{kPa}$ with a flow rate of $4 \mathrm{mg} / \mathrm{s}$. The pump model suggests that the pump efficiency remains constant at its maximum over the operating range, and the calculation result agrees well with the data (Figure 7). At the maximum speed achieved, the turbine model predicts $0.073 \mathrm{~W}$ of mechanical power production and an isentropic efficiency of $16 \%$ with $\mathrm{Re}=186$.

Based on the system model calculation, out of the total power produced by the turbine, $10 \%$ was consumed by the viscous pump, while the rest was dissipated by other components through viscous drag (Figure 8). In the calculation, the ungrooved part of the seal was assumed to be wet. In Figure 8, the chart was obtained for the maximum speed, but the distribution was similar for other speeds. Turbine bar indicates power production, while the others represent consumption or dissipation. The thrust bearing (TB) and seal were intentionally designed for high drag in order to mimic the load of a generator that would be integrated on the rotor for a Rankine cycle micro power generator. These results suggest that up to $75 \%$ of the turbine mechanical power could be available for power generation with redesigned seals and thrust bearing.

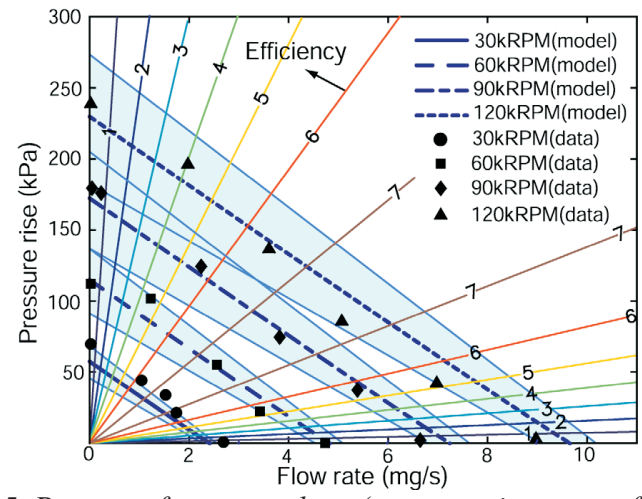

Figure 5. Pump performance chart (pressure rise versus flow rate) for various rotor speeds. Shaded areas represent uncertainty of the gap between the rotor and the pump in modeling, which is $1+1-$ 0.25 um. Contours of pump efficiency (in percent) are also shown, emanating from the origin.

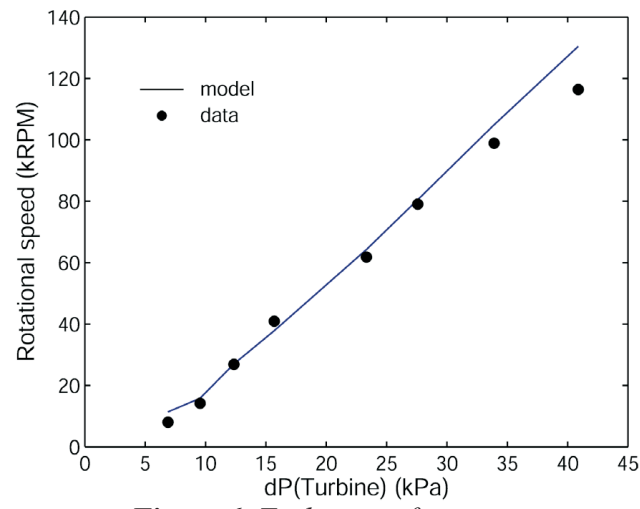

Figure 6. Turbine performance 


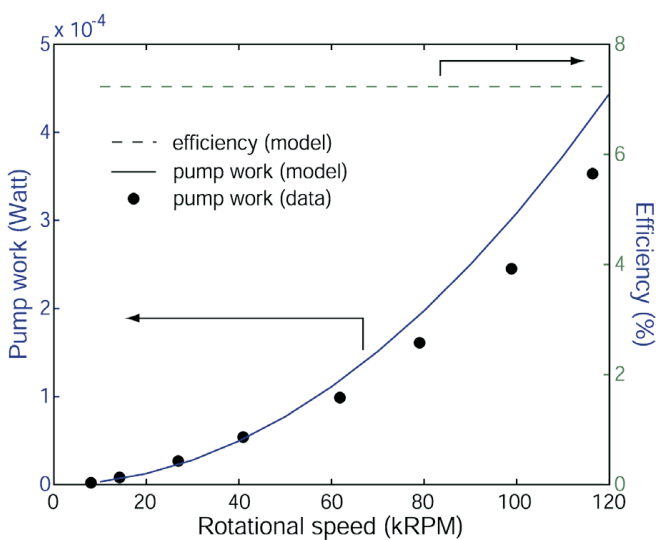

Figure 7. Pump performance. The pump work is defined as the product of the pressurization and the volumetric flow rate, which were individually measured, and the pump efficiency as the ratio of pump work to consumed power by viscous drag in the pump.

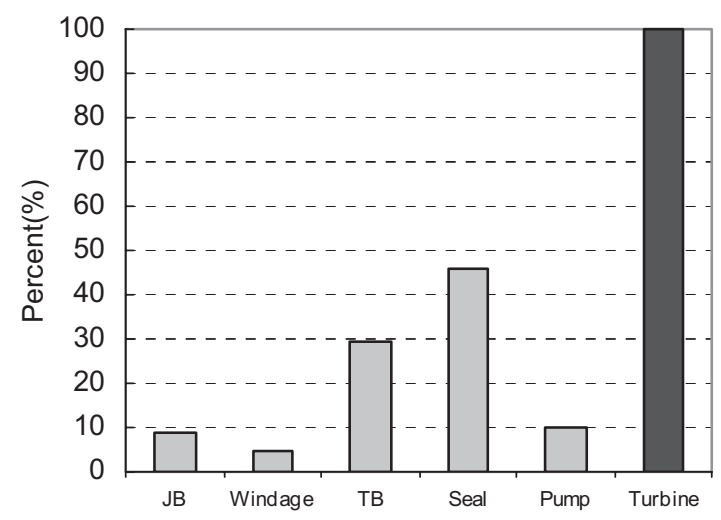

Figure 8. Power consumption budget of the turbopump (model)

\section{PROJECTED PERFORMANCE OF A MICRO RANKINE POWER GENERATOR}

The measured performance, especially the rotor speed, is still far lower than designed. However, these and previous results [3] validate our component and system models. Based on the model predictions at the design speed, the turbine would have $70 \%$ of isentropic efficiency and the pump 7\%. This estimation of the efficiencies is close to the assumptions of Mueller and Fréchette [6], which suggest that the whole micro Rankine power generation system could produce several watts of electric power with 1-12\% of thermal efficiency, depending on the heat addition and discharge conditions, for a similar size device as the current one.

As expected, the pump efficiency is relatively low compared to the MIT micro compressor $(50-70 \%$ in optimum operations [1]), which is part of the Brayton cycle micro gas turbine. However, the power consumed by the pump is almost trivial compared to the turbine power available. In contrast, the micro compressor inherently consumes a large portion of the turbinegenerated power, which results in poor thermal efficiency for a micro gas turbine of about 2-3\% [7].

\section{CONCLUSION}

A micro turbopump device with a multi-stage turbine and viscous pump supported on gas-lubricated bearings has been developed and demonstrated. The device was designed using analytical models supported by CFD, and was made of five bonded wafers, which went through 14 photolithography and etching processes. The $4 \mathrm{~mm}$ diameter rotor was spun up to $116,000 \mathrm{rpm}$ pumping water at the rate of $4 \mathrm{mg} / \mathrm{s}$ with $88 \mathrm{kPa}$ of pressurization. At the maximum speed reached, the turbine produced $0.073 \mathrm{~W}$ of mechanical power, of which $10 \%$ was consumed by the viscous pump. The pump performance chart was also completely characterized for speeds up to $120,000 \mathrm{rpm}$, and has shown $7.2 \%$ of maximum efficiency over the range of operating speeds. The rotational speed was limited by axial balance limitations and work is on-going to increase the operating range. Based on the test results, the improvement in operating speed is expected to lead to reasonable thermal efficiency of the whole Rankine power generation system.

This work proves the concept of the rotating subsystem for a micro Rankine power system and provides a validated design basis for future development. The technology demonstrated herein will also contribute to the development of other types of power MEMS, such as gas turbines, coolers, and pumps.

\section{ACKNOWLEDGEMENTS}

This work was supported by the NASA Glenn Research Center, Alternate Fuels Foundation Technologies program (contracts NAS3-02118 and NAS3-03105), monitored by Dr. Glenn Beheim. The authors gratefully acknowledge this support.

The fabrication work was performed in part at the Cornell NanoScale Science and Technology Facility (CNF), a member of the National Nanotechnology Infrastructure Network, which is supported by the National Science Foundation (Grant ECS 0335765).

\section{REFERENCES}

[1] A. H. Epstein, "Millimeter-Scale, Micro-Electro-Mechanical Systems Gas Turbine Engines," Journal of Engineering for Gas Turbines and Power, Vol. 126, pp205-226, April 2004.

[2] L. G. Fréchette, C. Lee, S. Arslan, Y. C. Liu, "Design of a Microfabricated Rankine Cycle Steam Turbine for Power Generation," Proc. ASME Int'l Mech. Eng. Congress and Expo. (IMECE'03), Washington, D.C., November 16-21, 2003.

[3] C. Lee, and L. G. Fréchette, "Demonstration and characterization of a Multi-Stage Silicon Microturbine," Proc. ASME Int'l Mech. Eng. Congress \& Expo., Orlando, FL, November 5-11, 2005, Paper IMECE2005-81435

[4] L. G. Fréchette, , S. A. Jacobson, K. S. Breuer, F.F. Ehrich, R. Ghodssi, R. Khanna, C.W. Wong, X. Zhang, M.A. Schmidt, A.H. Epstein, "High-Speed Microfabricated Silicon Turbomachinery and Fluid Film Bearings," IEEE/ASME J. of MEMS, Vol. 14, No.1, 2005.

[5] C. Lee, "Development of a microfabricated turbopump for a Rankine vapor power cycle," Ph.D Thesis, Columbia University, February 2006.

[6] N. Mueller, and L. G. Fréchette, "Performance Analysis of Brayton and Rankine Cycle Microsystems for Portable Power Generation," Proc. ASME Int'l Mech. Eng. Congress \& Expo., New Orleans, Louisiana, Nov. 17-22, 2002.

[7] J. M. Protz, "An Assessement of the Aerodynamic, Thermodynamic, and Manufacturing Issues for the Design, Development, and Microfabrication of a Demonstration Micro Engine," Ph.D Thesis, Massachusetts Institute of Technology, September 2000. 